\title{
IMPLEMENTASI KEPUTUSAN WALIKOTA BATU NO. 180 TAHUN 2010 TENTANG PEMBENTUKAN, PEMBINAAN DAN KEPENGURUSAN KELOMPOK INFORMASI MASYARAKAT DESA/KELURAHAN KOTA BATU (STUDI PADA DINAS KOMINFO KOTA BATU)
}

\author{
Heru Subagyo; Cakti Indara Gunawan; Cahyo Sasmito \\ Program Studi Ilmu Administrasi Negara, Sekolah Pasca Sarjana \\ Universitas Tribhuwana Tunggadewi \\ Email:subagyoheru5@gmail.com
}

\begin{abstract}
The Community Information Group (KIM), formerly known as KELOMPENCAPIR (Reader and Pirsawan Listening Group), is still needed by the community until now, other than as a Distributor or Community Information Agent. It functions as a Negative Information Filter (Hoax). This research began in September 2018 until December 2018. The informants of this research are the Head of Partnership and Collaboration in the Field of Communication and Information Communication Batu, and the Chairperson of KIM Batu City. The data validity checking technique used in this study is to use the Triangulation Technique. The results of this study indicate that the Implementation of Formation, Development and Management of KIM in the Village / Village in Batu City has been going well according to the duties and functions of each Implementer. Supporting Factors in Implementation are clear Legal Regulations / Umbrellas, Enthusiastic and Good Community Participation. Inhibiting Factors in Implementation are Facilities and Infrastructure, Education level, Limited Operational Cost Budget.
\end{abstract}

Keyword: Implementation; KIM Policy; Communication

Abstrak: Kelompok Informasi Masyarakat (KIM) yang dulu dikenal dengan nama KELOMPENCAPIR (Kelompok Pendengar Pembaca dan Pirsawan) keberadaanya sampai saat ini masih dibutuhkan sekali oleh Masyarakat,selain sebagai Penyalur atau Agen Informasi Masyarakat.berfungsi sebagai Penyaring Informasi Negatif (hoax). Penelitian ini dimulai pada bulan September 2018 sampai dengan Desember 2018, penelitian dilakukan di Dinas Kominfo Kota Batu. Informan penelitian ini adalah , Kasi Kemitraan dan Kerjasama Bidang Komunikasi Diskominfo Batu, dan Ketua KIM Kota Batu. Teknik pemeriksaan keabsahan Data yang digunakan dalam penelitian ini adalah menggunakan Teknik Trianggulasi. Hasil penelitian ini menunjukan bahwa Implementasi Pembentukan,Pembinaan dan Kepengurusan KIM Desa/Kelurahan Kota Batu dilaksanakan sesuai harapan masing-masing Implementator. Faktor yang menjadi Pendukung dalam Implementasi adalah Regulasi/Payung Hukum yang jelas,Antusias dan Partisipasi Masyarakat yang Baik. Faktor Penghambat dalam Implementasi adalah Sarana dan Prasarana, tingkat Pendidikan, Anggaran Biaya Operasional yang terbatas.

Kata Kunci: Implementasi; Kebijakan KIM; Komunikasi

\section{PENDAHULUAN}

Kota Batu telah memiliki 24 KIM yang berada di 19 Desa dan 5 Kelurahan yang terbentuk sejak Tahun 2005, kegiatannya adalah memberikan informasi/berita/penyuluh pembangunan secara teratur dan terus menerus serta menyerap pesan-pesan program dan kebijaksanaan pembangunan Pemerintah Kota Batu. KIM Kota Batu ikut dalam 
pengembangan Wisata terutama, menyangkut kepentingan terciptanya kemandirian kepariwisataan dan perekonomian dalam satu Informasi yang terintegrasi (Gunawan,2015 : 8)

Kelompok Informasi Masyarakat (KIM) merupakan suatu kelompok masyarakat yang aktif bergerak untuk mengikuti dan mengembangkan kemajuan desa menuju sejahtera. KIM melalui pengawasan dan pembinaan Dinas Komunikasi dan Informatika melaksanakan agenda dua tahunan dengan menggelar Pekan KIM dengan berbagai kegiatan sesuai dengan era perkembangan global yang ada.(Permana,Sasmito \& Gunawan, 2018).

\section{Gambar: Kerangka Pemikiran}

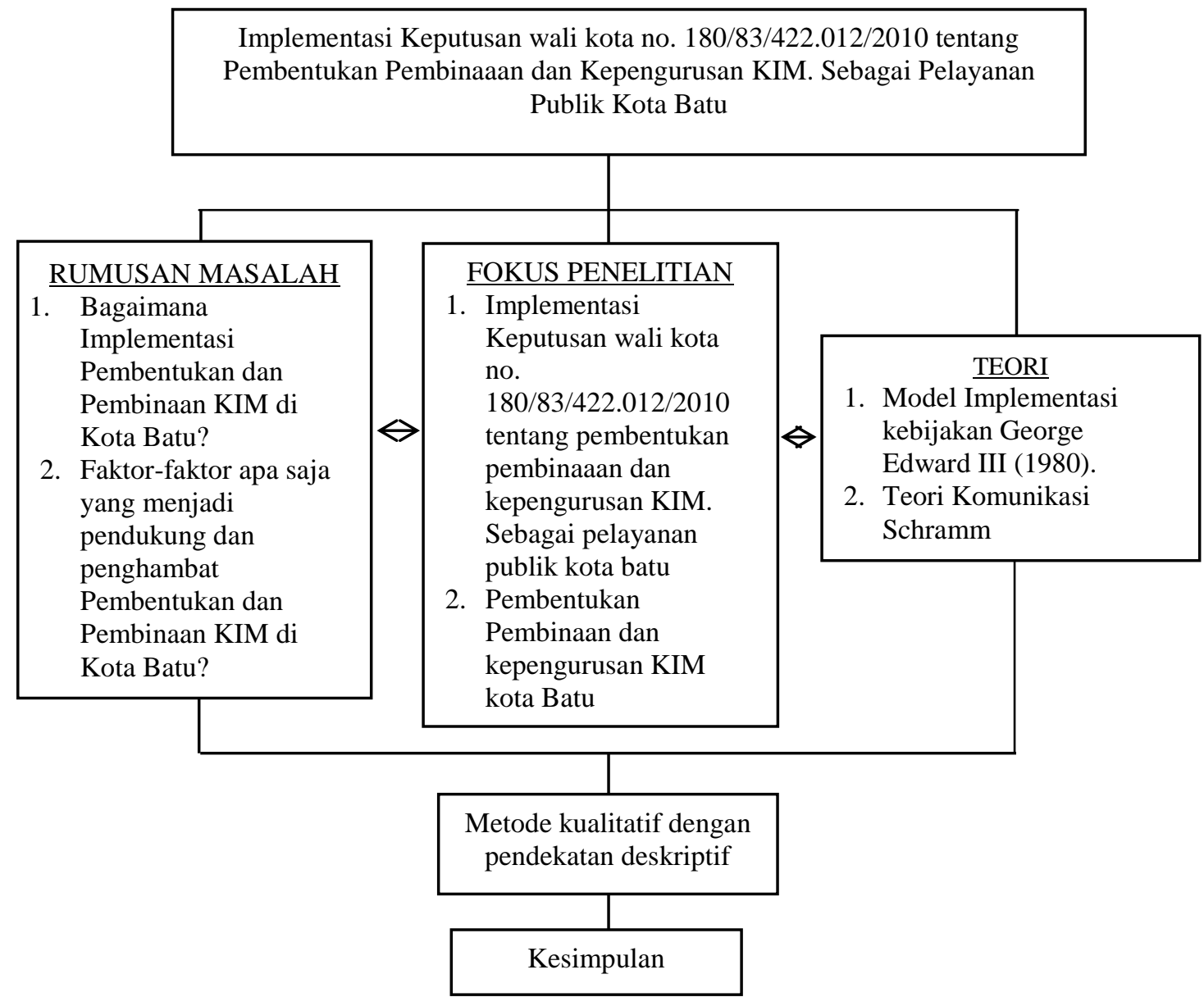

Sumber: Diolah Peneliti, 2019

\section{METODE PENELITIAN}

- Penelitian ini dilakukan dengan menggunakan metode kualitatif yang bertujuan untuk mengetahui lebih mendalam mengenai Implementasi Keputusan Walikota Batu No. 180 Tahun 2010 tentang Pembentukan, Pembinaan dan Kepengurusan Kelompok Informasi Masyarakat Desa/Kelurahan Kota Batu. Instrumen penelitian adalah peneliti sendiri, interview guide, catatan lapangan dan handphone (kamera atau tape recorder). Penelitian ini mengumpulkan data primer dan data sekunder. Data primer diperoleh dari hasil wawancara mendalam terhadap para informan yang berhubungan dengan fokus penelitian. Sedangkan data sekunder diperoleh dari dokumen dan hasil observasi di lokasi penelitian. Data yang 
diperoleh selanjutnya dianalisis melalui tahap reduksi data, penyajian data, dan penarikan kesimpulan. Untuk menguji keabsahan data, penelitia menggunakan triangulasi tehnik.

\section{HASIL DAN PEMBAHASAN}

\section{Pembahasan Implementasi Keputusan Walikota No.180/83/422.012/2010 tentang Pembentukan, Pembinaan dan Kepengurusan KIM di Kota Batu}

Dalam membahas tentang Implementasi Keputusan Walikota No.180/83/422.012/2010 tentang Pembentukan, Pembinaan dan Kepengurusan KIM di Kota Batu yang dibutuhkan adalah landasan yang dapat membandingkan dari hasil wawancara dan observasi yang dilakukan peneliti.

Dari hasil wawancara menunjukan sejauh ini sudah terlaksana, salah satu bentuknya adalah dengan melakukan pelatihan Jurnalistik, MC, Public Speaking dan pembuatan Vlog. Selain itu kita juga Rutin setiap bulannya melaksanakan Anjangsana ke masing-masing KIM sekota Batu. Wawacara yang dilakukan oleh Peneliti menunjukan bahwa pentingnya pembentukan kelompok Binaan kepada Masyarakat terkhusus dalam Bidang Teknologi Informasi (Muliawan,Sasmito \& Gunawan, 2019).

Obervasi menunjukan dalam Pembinaan Masyarakat di Bidang Teknologi dapat mempermudah Masyarakat dalam Mempromosikan Daerahnya seperti halnya kota Batu yang merupkan Daerah atau kawasan Wisata. Hal ini terlihat dari Pelatihan yang dilaksanakan seperti pembuatan video Vlog, yang menjadi salah satu Sarana Media Promosi bagi Masyarakat.

Hasil observasi dan Wawancara yang dilakukan, mengacu pada Keputusan Walikota Batu no.180/83/422.012/2010 Tentang Pembentukan Pembinaan Dan Kepengurusan Kelompok Informasi Masyarakat (KIM) Desa/Kelurahan, bahwa dalam rangka untuk meningkatkan dan mendukung program Informasi Pembangunan serta untuk memasyarakatkan dan membudayakan nilai-nilai semangat pembangunan dan gotong-royong ke seluruh lapisan masyarakat Kota Batu, maka perlu dibentuk Kelompok Informasi Masyarakat (KIM) Desa/Kelurahan.

Data Dinas Komunikasi dan Informatika Kota Batu, per Januari 2017 di Kota Batu KIM berjumlah 24. KIM diKota Batu ada yang masih bersifat konvensional atau tradisional . sudah ada KIM yang Profesional.

Seiring perkembangan dan kemajuan Teknologi, sudah selayaknya jika keberadaan KIM itu ditata dan disesuaikan dengan Standartisasi Pendirian dan Pengelolaanya, karena keberadaan atau jumlah KIM diatas merupakan Aset yang harus dikelola dengan baik. Sehingga kedepan KIM Kota Batu Menjadi Agen dan Pengelola Informasi yang Handal dan berdaya guna, bisa eksis di tengah-tengah Masyarakat seiring perkembangan Teknologi Informasi .

\section{a. Komunikasi}

Menurut Teori Komunikasi Schramm adalah Kepanjangtangan dari Pemerintah. Dimana Pemerintah sebagai Komunikator dan KIM sebagai Komunikan. Pesan berupa Peraturan-Peraturan yang di Sosialisasikan kepada Masyarakat. Sedangkan umpan balik berupa Respon dari Masyarakat untuk menindaklanjuti isi pesan tersebut. Sulila (2015: 50), berangkat dari asumsi yang mengatakan bahwa implementor kebijakan akan melaksanakan apa yang diterima dan dipahami dalam suatu kebijakan semakin baik komunikasi yang dilakukan maka akan semakin dekat pula produk kebijakan dengan tingkat efektifitasnya. 
Hasil wawancara menyatakan bahwa Sejauh ini komunikasi yang dilakukan sudah berjalan dengan baik sesuai dengan harapan dari pembentukan KIM ini sendiri, selain itu untuk komunikasi sendiri sejauh ini telah dibangun relasi dengan berbagai kalangan, dimana hal ini sangat dibutuhkan untuk membant dalam pelaksanaan program KIM ini.

Hasil observasi menunjukan Komunikasi yang dilakukan berjalan dengan baik dimana terlihat dalam berbagai Rapat Koordinasi yang dilakukan. Diskusi Rutin dilaksanakan dengan para Kelompok Informasi Masyarakat. Maka disimpulkan dalam Program setiap Elemen tidak dapat berjalan dengan sendirinya, namun saling berkoordinasi diantara satu dengan lainnya. implementasi kebijakan.

Peneliti dapat menyimpulkan Konsistensi implementator mempengaruhi

Hal ini sejalan Penelitian yang dilakukan Syarif (2015) menyebutkan Pola Komunikasi yang dilakukan KIM ternyata bisa mensukseskan Program Pemerintah dalam konteks Penelitian di Bidang Swasembada Pangan. dengan Teknis komunikasi pendekatan Sosial.

\section{b. Sumber Daya Manusia}

Pada dasarnya teori yang dikemukan oleh Bhinadi (2017: 24) menyebutkan bahwa pada hakikatnya pemberdayaan masyarakat salah satunya haruslah memperkuat potensi atau daya (empowering) tersebut, pada konteks ini adalah sumber daya manusianya. Disisi lain Sulila (2015: 52-53), berpendapat bahwa dalam pandangan ini perintah-perintah yang harus diimplementasikan wajib diteruskan secara cermat, jelas dan konsisten akan tetapi jika para pelaksana mempunyai sumber daya yang sangat terbatas yang diperlukan untuk mengimplementasikan kebijakan-kebijakan maka dapat dipastikan pelaksanaan implementasi kebijakan berjalan tetapi tidak sebagaimana yang diharapkan adapun sumber daya yang penting adalah meliputi: penempatan pegawai staf (staffing)yang memadai, informasi (imformation), wewenang (authority) dan fasilitas.

Hasil wawancara menyebutkan bahwa pemerintah telah berusaha menyediakan yang terbaik bagi masyarakat demi kelancaran program ini. Namun keterbatasan sumber daya manusia yang memadai serta tenaga ahli terkadang menjadi kendala yang dihadapi dilapangan. Dari observasi penelitian menunjukan bahwa keterbatasan sumber daya manusia menjadi suatu tantangan yang sangat mempengaruhi, ini terlihat dari pejabat yang menangani Kelompok Informasi Masyarakat yang selalu berganti-ganti ataupun pindah membuat pekerjaan sedikit terganggu, serta tidak adanya kompetisi dibidang komunikasi yang mahir dibidang pembinaan masyarakat.

Maka Peneliti menyimpulkan bahwa pendukung yang dapat dipakai untuk melakukan kegiatan program seperti dana dan sarana prasarana.

Pembentukan KIM sendiri atas dasar kesadaran Masyarakat tentang arti pentingnya sebuah pesan informasi yang berguna dan bermanfaat bagi Masyarakat. Pembinaan yang dilakukan oleh Pemerintah berupa Pemberdayaan melalui Ketrampilan,berupa Bidang Komunikasi seperti mengisi Konten di WEB,membuat Video Volg dan Kemampuan Publik Speaking.

\section{c. Birokrasi}

Sulila (2015: 55-56), struktur organisasi adalah susunan komponen (unit-unit) kerja dalam organisasi yang menujukan adanya pembagian kerja serta adanya kejelasan pembagian 
fungsi-fungsi atau kegiatan yang berbeda-beda di integrasikan dan dikoordinasikan, selain itu struktur organisasi menunjukan spesifikasi pekerjaan, bentuk-bentuk perintah dan laporan akhir. Adapun aspek-aspek dalam stuktur Birokrasi, yaitu: adanya Standart Operasional Prosedur (SOP) yang mengatur tata aliran pekerjaan dalam pelaksanaan program dan fragmentasi adalah upaya penyebaran tanggungjawab pada suatu area kebijakan diantara beberapa unit organisasi (Sulila, 2015: 55-56).

Hasil wawancara menyebutkan Implementasi Keputusan Walikota memiliki Tatanan Birokrasi, bahkan dalam pelaksanaan memiliki Badan Hukum yang jelas dalam pelaksanaannya Observasi yang dilakukan oleh Peneliti menunjukan Struktur Organisasi sudah tertata dengan baik dalam Implementasinya.

\section{Faktor Pendukung Dan Penghambat Implementasi Keputusan Walikota No.180/83/422.012/2010 Tentang Pembentukan, Pembinaan dan Kepengurusan KIM Di Kota Batu}

\section{a. Faktor Pendukung}

Hasil wawancara menunjukan bahwa dalam Implementasi pembentukan KIM ini telah memiliki Regulasi atau payung hukum yang jelas hal tersebut dapat memperkuat kita dihadapan Negara terutama dihadapan Masyarakat. Hal lain yang menjadi factor pendukung adalah kebutuhan akan Informasi yang semakin hari semakin cepat dalam menghadapi maraknya Teknologi digital diera Modern saat ini menuntut Masyarakat untuk cepat tanggap serta menerima berbagai Informasi ataupun berbagai pesan yang bermanfaat.

\section{b. Faktor Penghambat}

Anggaran perbulan setiap KIM diberi dana 200 ribu dirasa sangat minim. Selain itu Sarana dan Prasarana yang belum memadai, seperti peralatan Komputer, Jaringan Internet,serta Meja kursi belum ada. Mereka menggunakan HP Android milik Pribadi dan juga Laptop. Sekretariat yang masih mendompleng Kantor Desa,sebagian besar Keberadaan KIM berada di Kantor Desa/Kelurahan untuk memudahkan Administrasi Surat Menyurat maupun Rapat.

Hasil observasi penelitian menunjukan Sarana dan Prasarana sangatlah dibutuhkan dalam pelaksanaan Kelompok Informasi Masyarakat dilapangan. Jika dilihat dari Program yang dilaksanakan merupakan program yang bergerak dibidang teknologi informasi maka Media Elektronik sangatlah dibutuhkan untuk askses penunjang dalam pembelajaran tentang IT. Seperti diketahui masih banyak dari pelaksana KIM belum mampu menguasai IT disebabkan tingkat pendidikan kurang memadai. Oleh karena, penyediaan alat-alat Komunikasi sangatlah dibutuhkan

\section{KESIMPULAN}

Proses Implementasi Keputusan Walikota Batu tentang Pembentukan, Kepengurusan dan Pembinaan Masyarakat yang telah dilakukan oleh Kelompok Informasi Masyarakat di Kota Wisata Batu melalui, tahapan sebagai berikut memberikan Penyadaran tentang Arti pentingnya Informasi, Pengkapasitasan, Pemberian Daya, membuat Rencana Aksi dan Implementasi,serta melakukan Evaluasi.

1. Komunikasi 
Komunikasi dalam Impementasi keputusan Walikota Batu No.180 Tahun 2010 tentang Pembentukan, Pembinan dan Kepengurusan KIM sejauh ini telah berjalan dengan sangat baik dan, melibat semua unsur yang berpengaruh dalam mengembangkan program yang direncanakan bersama.

2. Sumber Daya Manusia

Sumber Daya Manusia yang terbatas mengakibatkan tidak berjalanya kegiatan secara maksimal karena kurangnya Pengawasan yang baik. Serta keterbatasan Pendidikan dan penguasaan IT,menjadi hambatan terlaksananya Program.

3. Birokrasi

Struktur Organisasi yang Tertata dengan rapi sesuai Standar Operasional yang diakui, telah memiliki Regulasi atau Payung Hukum yang jelas.

4. Faktor Pendukung dan Penghambat

Regulasi atau Payung Hukum yang jelas, Partisipasi, serta Antusias Masyarakat dalam menerima Program sebagai kebutuhan Informasi. Sedangkan faktor penghambatnya adalah kurangnya Tenaga Ahli dalam melakukan Pendampingan, kurang SDM Pengurus dan Anggota serta Tingkat taraf Pendidikan kurang memadai, Sarana dan Prasarana tidak menunjang, serta keterbatasan Biaya.

\section{DAFTAR PUSTAKA}

Subarsono, AG. 2013. Analisis Kebijakan Publik, Konsep, Teori dan Aplikasi. Yogyakarta: Pustaka Pelajar.

Bhinadi, Ardito. 2017. Penanggulangan Kemiskinan \& Pemberdayaan Masyarakat (Studi Kasus Daerah Istimewa Yogyakarta. Yogyakarta: Grup Penerbit (Budi Utama).

Gunawan, Cakti Indra. 2015 Sistem Informasi manajemen \& E-Government. Purwokerto: CV. IRDH.

IRDH.

2016 Sistem Informasi manajemen \& E-Government. Purwokerto: CV.

an, Iwan, Cahyo Sasmito,Cakti Indra Gunawan . 2019. Implementasi Penyaluran dana

Desa di Kabupaten Sambas Kalimantan Barat. Jurnal Ilmu Adminstrasi (JIA).Vol.16 No.1 .P. 97-111.

Moleong, Lexy, J. 2017. Metodologi Penelitian Kualitatif Edisi Revisi. Bandung: PT Remaja Rosdakarya.

Nasdian, Fredian Tony. 2014. Pengembangan Masyarakat. Bogor: Departemen Sains Komunikasi Dan Pengembangan Masyarakat IPB dengan Yayasan Pustaka Obor Indonesia.

Nugroho, Riant, D. 2014. Public Policy: Dinamika Kebijakan Publik, Analisis Kebijakan Publik, Manajemen Politik Kebijakan Publik, Etika Kebijakan Publik, Kimia Kebijakan Publik. Jakarta: PT. Elex Media Komputindo.

Nugroho, Riant. 2015. Kebijakan Publik Di Negara-Negara Berkembang. Yogyakarta: Pustaka Pelajar.

Sugiyono. 2015 Metode Penelitian Kuantitatif, Kualitatif dan $R \&$ D. Bandung: CV. Alfabeta.

Sulila. 2015. Implementasi Dimensi Pelayanan Publik Dalam Konteks Otonomi Daerah. Yogyakarta: CV. Budi Utama.

Wahab, Sholihin Abdul. 2015. Analisis Kebijakan, Dari Formulasi ke Penyusunan, ModelModel Implementasi Kebijakan Publik. Jakarta: PT Bumi Aksara. 